\section{Openness in Adoption: Psychological Outcomes Among Birth Mothers}

Laura Pastrana, Shireen Rezaei, Kailee Brown, Steve Sunday W WEBER STATE

\section{LITERATURE REVIEW}

Siegel (2013) conducted a study on the effect of open adoptions on adopted children's lives. The overall findings of this project showed that adoptive parents were generally more positive about the adoption when they knew the birth parents personally.

Grotevant et. Al. (2007) looked into the separation between families with no contact, families that stopped contact, families with contact not including meetings, and families with face-to-face contact between the adoptee, birth mother, and adoptive parents. The study conducted interviews to learn more about views regarding various openness

arrangements. The results from this research showed that participants having no contact and participants already having contact both want the contact to increase in the future

Cushman, Kalmuss, \& Namerow, (1997) looked into the outcomes of the adoption triad in relation to the amount of openness in an adoption. It also included the mental and psychological outcomes of the three parties involved The data revealed parthes that open adoption features such as visiting/phoning have a strong relation with positive outcomes for birth mothers.

\section{METHODS}

This study was conducted by administering a cross-sectional selfadministered online survey Constructing an online survey allows us to be flexible in the way we send the survey out while reaching a the survey out while reaching a variety of birth mothers. The survey asked a variety of questions including basic demographic characteristics how open their experience with adoption was, the age of placement, year of adoption, and more. We asked these questions in order to better understand if openness in adoption affects the satisfaction and psychological outcomes of birth mothers.

\section{DEMOGRAPHICS}

How does the degree of openness in an adoption impact psychological
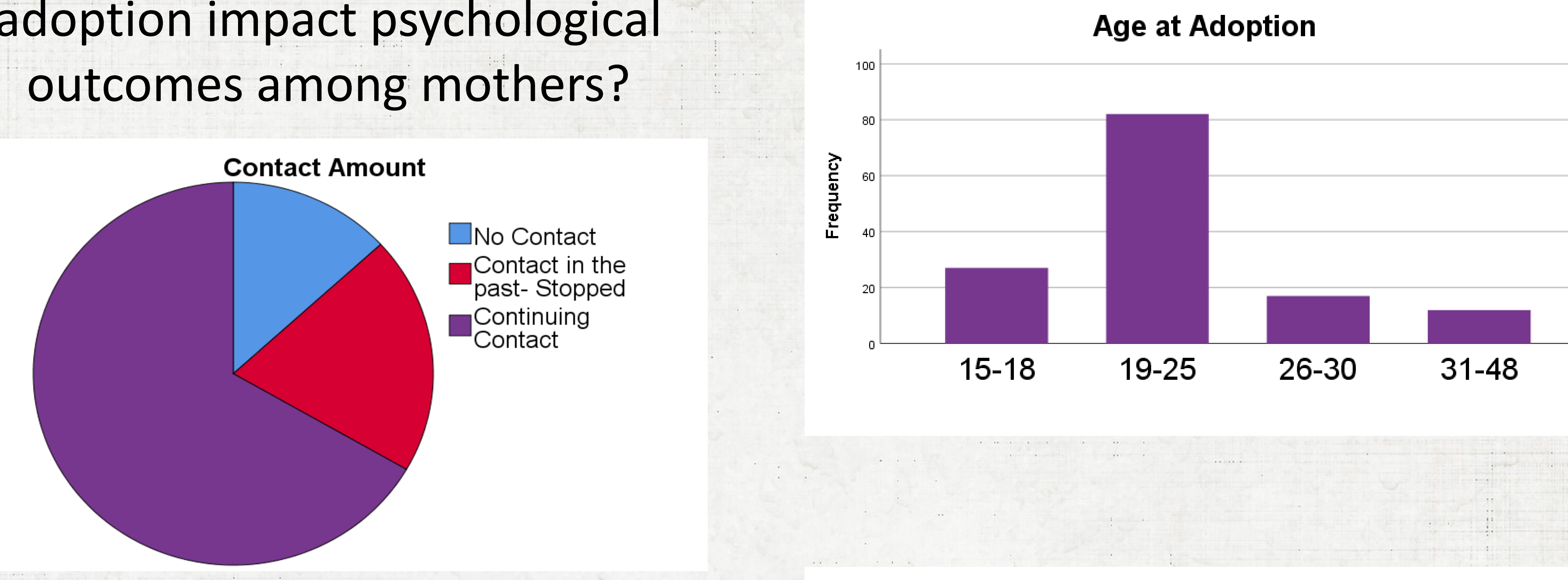

Household Income at Adoption
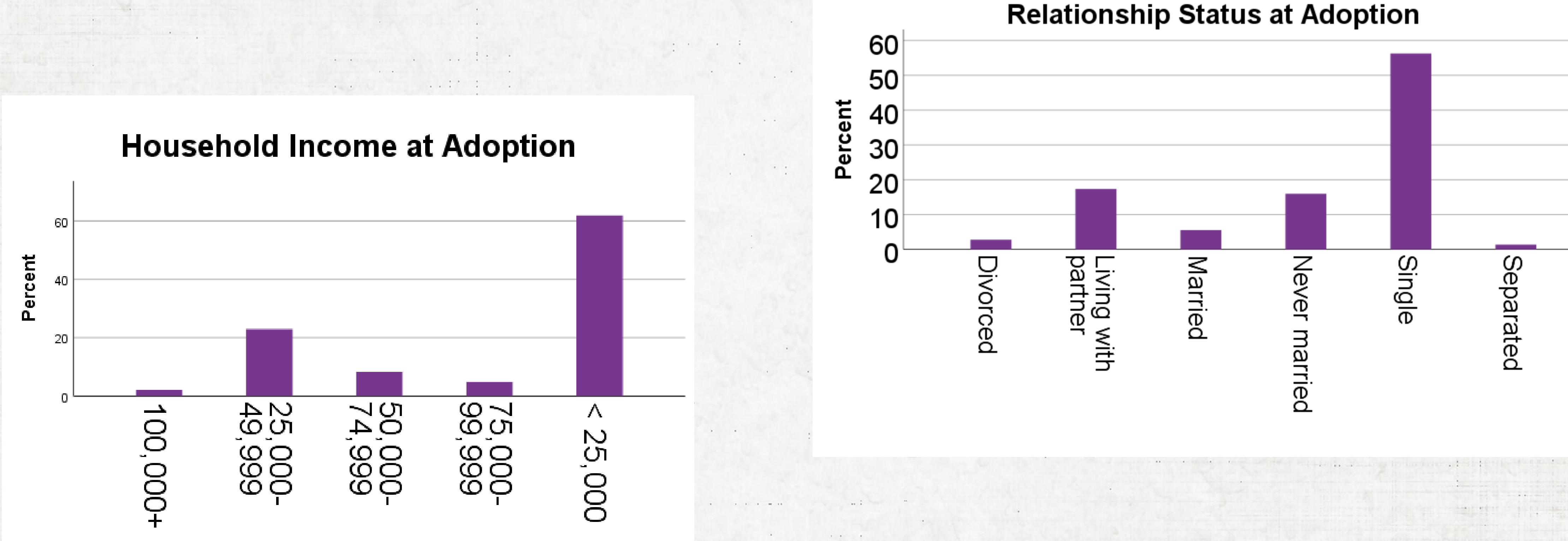

\section{FINDINGS}

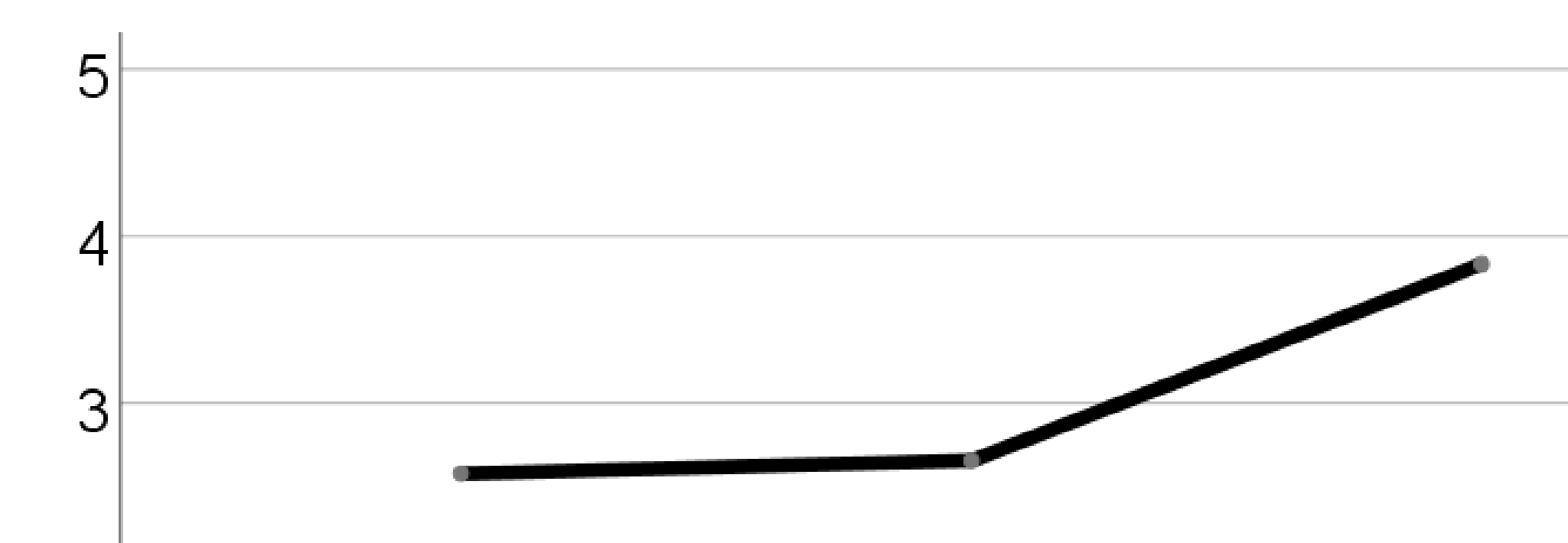

No Contact $\begin{gathered}\text { Had Contact - } \\ \text { Stopped }\end{gathered} \begin{gathered}\text { Continuous } \\ \text { Contact }\end{gathered}$
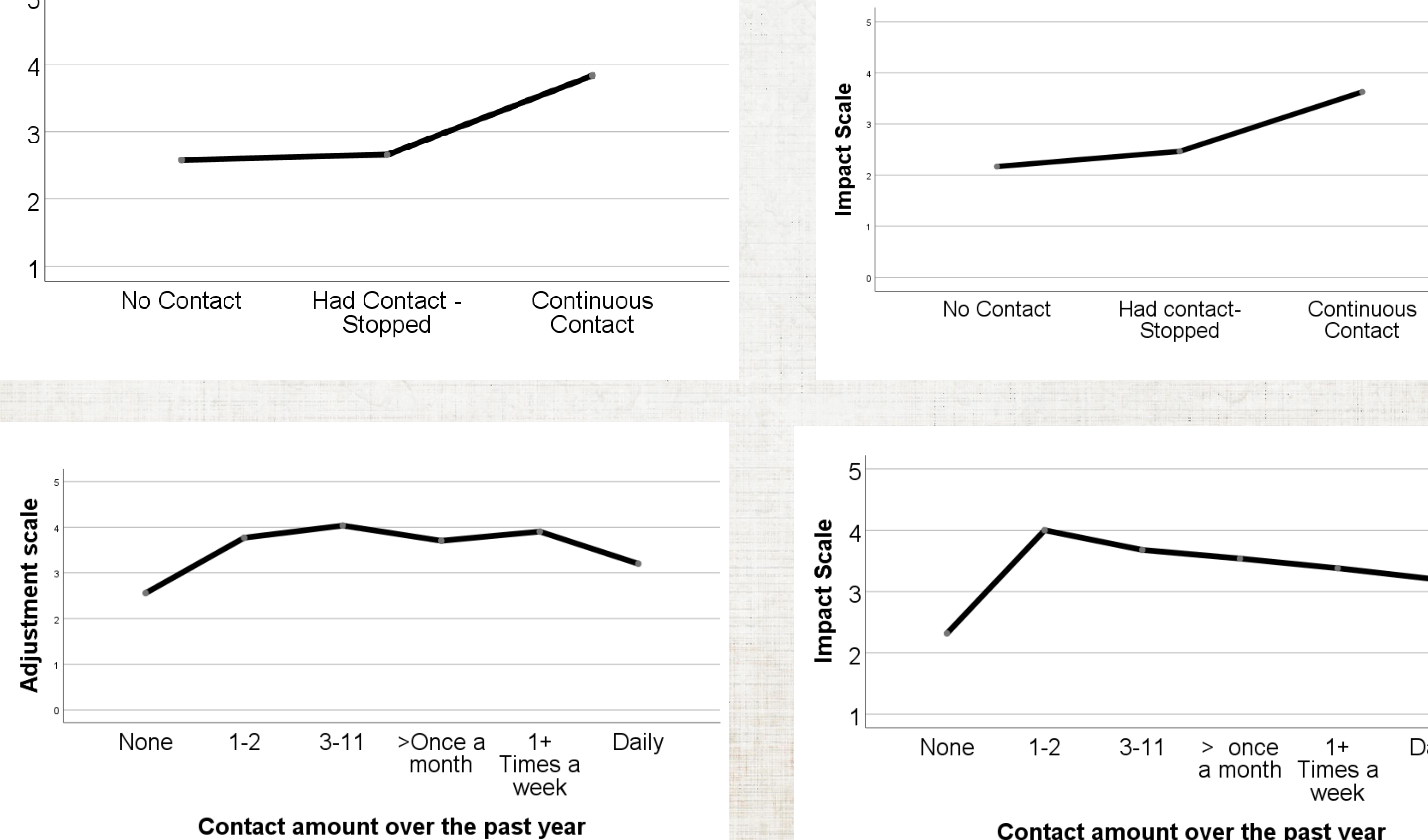

outcomes among mothers?

\section{CONCLUSION}

- Significant differences were found between the no contact group and the 3 11 times a year, more than once a month, and the one or more times a week groups.

- Significant differences were found between the groups with no contact or contact that had stopped and the group with continuous contact.

- . Significant differences were found in the group that had no contact with their relinquished child over the past year and those that had contact once or twice, 3 11 times, more than once a month, and more than once a week. There was no significant difference between the no contact group and the daily one.

- Significant differences were found between the groups with no contact or contact that had stopped and the group with continuous contact

Overall, how well do you feel you have adjusted

to the decision to

relinquish your child for

adoption?

1-Not well at all

2-Not well

3-Neutral

4-Somewhat we

What impact has the adoption had on your life? 1-Overall Negative Impact 2-Positive impact at first 3-Mixed impact- currently both positive and negative 4-Negative impact at first, but more positive now 5-Overall positive impact

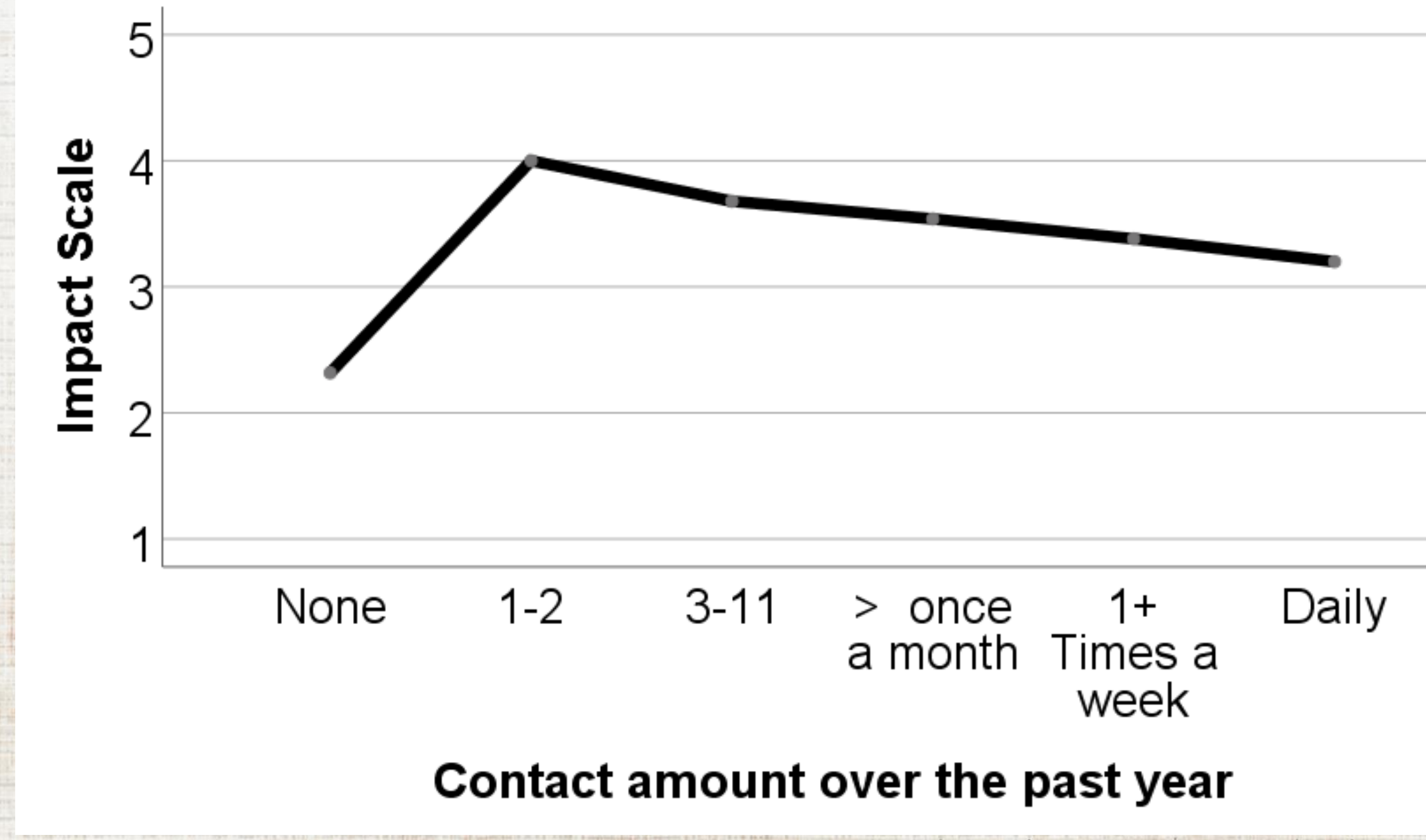

\section{References}

